\title{
Improving the Physical Fitness of Preschool Children with Mental Disorders by Means of Recreational Aerobics
}

\author{
Anastasia V. Stafeeva ${ }^{1}$, Svetlana S. Ivanova ${ }^{1}$, Gerold L. Drandrov ${ }^{2}$, Irina Y. Burkhanova ${ }^{1}$, \\ Nikolay B. Vorobyov ${ }^{1}$, Olga V. Reutova ${ }^{1}$, Anna V. Bylushkina ${ }^{3}$ \\ ${ }^{1}$ Department of Physical Education Theoretical Foundations, Kozma Minin Nizhny Novgorod State Pedagogical University, Nizhny Novgorod, \\ Russian Federation \\ ${ }^{2}$ Department of Sports Disciplines, I. Yakovlev Chuvash State Pedagogical University, Cheboksary, Russian Federation \\ ${ }^{3}$ Department of Physical Education, Nizhny Novgorod State Technical University, Nizhny Novgorod, Russian Federation
}

\begin{abstract}
Received: 18/12/2020
Accepted: 19/03/2020

Published: 20/02/2020

Abstract

The relevance of the topic presented is due to the fact that there is currently a contradiction between the increasing number of children with disabilities in preschool educational institutions, and the increasing requirements of the Federal State Educational Standard for Preschool Education to the level of development of health components. Step aerobics is one of the effective means of solving the problems of improving the health, motor activity and functional capabilities of preschool children. The study has developed and experimentally substantiated the content of recreational aerobics classes in preschool educational establishments for children with mental disorders. The positive influence of offered means on indicators of physical development and physical readiness of preschool children having mental infringements is revealed. The aim of this research is to develop and experimentally substantiate the content of recreational aerobics classes at a preschool educational institution for children with mental disabilities. The study found a positive impact of the proposed funds on the indicators of physical development and physical fitness of preschool children with mental disorders. The materials can be used in the process of physical education of preschool children with disabilities, as well as in physical education classes in kindergartens, child development centers, physical education, and fitness classes for children.
\end{abstract}

Keywords: preschoolers, Physical fitness, Mental disorders, Physical fitness, Functionality, Step-aerobics

\section{Introduction}

Early childhood is a period of intensive growth and development of the organism, high sensitivity to the influence of social environment, including preventive and healthimproving measures. It is at this age that the foundations of health, correct physical development are laid, motor skills and abilities are formed, and motor abilities are developed [1, 2,3]. At present, the problem of health care in preschool children is connected with the following group of contradictions:

- Between the different health patterns in the group and a single content, as well as the frontal content of the classes;

- Different dynamics of senitional periods of development and a single programme for their development in preschools;

- Between the age of children with disabilities in preschool institutions and the increased requirements of the Federal State Educational Standard for Preschool Education (FSES) for the level of development of health components. According to the Federal State Educational Standard, one of the priorities of preschool education institutions is to preserve the health and improve the physical fitness of preschool children. Presently, preschool educational institutions apply various approaches to improving and preserving the health of preschool children. Thus, such means as massage and finger gymnastics, "health paths and wiping with a "mitten" in a playful form are widely used $[4,5,6]$.
There is experience of combining physical education classes with logorithmic, which includes means of speech therapy, music and rhythmic and physical education, and also includes classes with elements of various sports such as football, basketball, tennis and others [7, 8, 9]. All these forms, according to the authors, have a positive impact on the health of children, but do not fully provide a differentiated approach provided that children with different levels of physical condition and disabilities (disabilities) [10, 11, 12].

One of the effective means in solving the problems of increasing the motor activity and functionality of the body of preschoolers, in our opinion, is the steppe-aerobics. In recent years, the arsenal of fitness equipment has increased technologies used in preschool educational institutions, which can be used in physical exercise classes and other recreational activities. Steppe aerobics classes are very popular. Stepaerobics is a complex of dance exercises performed on a special platform to dance music [13]. The peculiarities of steppe aerobics are that the pace of movement intensity of the exercises is set by the rhythm of musical accompaniment. Skilful and expressive performance of movements to music brings satisfaction and joy to a child. A musical melody, which has been intelligently matched to the movements, helps to consolidate the muscle feeling, and an auditory analyzer remembers the movements in connection with the sound of musical passages. All of this gradually cultivates musical

Corresponding author: Anastasia V. Stafeeva, Department of Physical Education Theoretical Foundations, Kozma Minin Nizhny Novgorod State Pedagogical University, Nizhny Novgorod, Russian Federation. E-mail: staffanastasiya@ yandex.ru 
culture, consolidating the habit of moving rhythmically, gracefully, and beautifully. Mastering new, more and more complex movements with musical accompaniment, children strive to measure them in time and space, to subordinate them to rhythmic drawing, requirements of plasticity and external expressiveness $[14,15]$. Despite a number of studies devoted to improving the process of physical education of preschool children, there are not enough practical developments and methodological recommendations for the use of step-aerobics in kindergartens [16 - 19]. In this regard, we consider the problem of revealing the methodological peculiarities of the use of steppe-aerobics in the process of physical education in preschool children, which would contribute to the preservation and promotion of health, the formation of those engaged in the need for systematic physical exercises.

\section{Methodological Framework}

The methodological basis of the study was the concept of personality-based approach, as well as the main provisions of the theory and methodology of physical education of preschool children and the theory and organization of adaptive physical education. Initially, the problem of mental development delay in domestic studies was justified by clinicians. The term "mental development delay" was suggested by G.E. Sukhareva [20]. The investigated phenomenon is characterized, first of all, by the slowed rate of mental development, personal immaturity, noncoarse disorders of cognitive activity, by structure and quantitative indexes differing from oligophrenia, with a tendency to compensation and backward development. On this basis, G.E. Sukhareva [20] identified six types of states, which should be separated from the notion of "oligophrenia":

1) intellectual disturbances observed in children with a slow (or delayed) pace of development due to unfavorable environmental and educational conditions;

2) intellectual disorders in prolonged asthenic conditions due to somatic diseases;

3) disorders of intellectual activity in various forms of infantilism;

4) secondary intellectual disability due to hearing, vision, speech, reading and writing impairment;

5) intellectual impairments observed in children at the residual stage and in the remote period of central nervous system infections and injuries;

6) intellectual disturbances in progenitor nervous and mental diseases.

In clinical and psychological structure of each of the listed variants of mental development delay there is a specific combination of immaturity of emotional and intellectual spheres. In special researches the concept of mental infantilism is used, which is understood as a variant of the detained development, which is shown in the unsuitable age of immaturity of the physical and mental status, not accompanied by gross violation of intelligence. Most of the work is aimed at studying various symptomatic pictures found in children with brain disorders. This is a category of children with a wide range of different psychopathological syndromes that lead to mental retardation $[21,22]$. This includes children with lesions of the central nervous system (CNS) (specific or diffuse), speech disorders, learning difficulties, perceptual disorders, hyperkinesia. In addition, this group includes children who do not have any neurophysiological disorders, but who nevertheless exhibit the same psychological symptoms as children with CNS impairment.

With the emergence of the genetic concept of the child's mental development, the psyche began to be considered as a reconstructed hierarchical structure integrating emerging functions into new indivisible functional systems, dependent to a large extent on the maturing of the central nervous system. Psychological adaptation of children with mental development delay is a problem the urgency of which is caused today by traditional demands of psychological and pedagogical, clinical and social practice and certain transformation of ideas about the psychogenetic essence of the given status, criteria of diagnostics, principles of the organization, character and volume of specialized aid [23 - 27]. In the context of the medical approach, mental disorders are considered as a syndrome of immaturity of mental or psychomotor functions and as a manifestation of delayed maturation of morphofunctional brain systems under the influence of some or other adverse factors [28-30].

\section{Results and Discussion}

In the experiment 12 children of the group of combined focus of preschool educational institution of Nizhny Novgorod took part during 2 years: for children with mental development delay (mental disorders) and speech disorders from 5 to 7 years old, who have such accompanying diseases as acute neurological syndrome, small brain activity (MMD), encephalopathy, scoliotic posture. During the experiment, steppe-aerobics classes were organized in a combined group and took the form of full health-improving and training sessions, lasting 30 minutes in the afternoon. A significant difference in the content and organization of stepping-aerobics classes for children with disabilities was the methods used to teach basic stepping-aerobics techniques and exercises aimed at developing physical qualities. Classes with children with disabilities began with games of low mobility, aimed at increasing attention, building and restructuring. In the main part of the lesson, a new element was taught, if a child is not confident in himself or herself, performs the exercise with mistakes, and "running on the move" is applied. As a result of the introduction of step aerobics classes into the process of physical education, at the end of the experiment a significant increase in the indicators of physical development and physical fitness of preschool children with mental disorders was identified. Moreover, the growth rates for all indicators show that the increase in physical development was due to the effective use of natural forces and physical exercise, and not only due to the natural growth of children. So, length of children of a body at the beginning of research has made $120,1 \pm 1,1 \mathrm{sm}$, at the end of research $123,0 \pm 1,1 \mathrm{sm}, \mathrm{p}<0,05$, differences are reliable. Growth rate was $15.2 \%$. The weight of a body at the beginning of experiment has made $20,14 \pm 0,98 \mathrm{~kg}$, at the end of experiment $-23,56 \pm 1,1 \mathrm{~kg}, \mathrm{p}<0,05$, distinctions are reliable. Growth rate $-15,7 \%$. We also found reliable differences between the results in the dynamics at the beginning and at the end of the experiment in indicators of hand dynamometry. The indicator of the right hand was $4.27 \pm 0.2 \mathrm{~kg}$ at the beginning of the experiment and $4.78 \pm 0.11 \mathrm{~kg}$ at the end of the experiment, the differences are reliable. Growth rate was $16.2 \%$. The indicator of the left hand made at the beginning of experiment $3,3 \pm 0,1 \mathrm{~kg}$, at the end of experiment $-3,7 \pm 0,09 \mathrm{~kg}$, differences are reliable. Growth rate was $15.1 \%$ (Table 1). Reliable differences have also been found in respiratory and cardiovascular system function indicators - lung capacity, blood pressure and hearth rate. Lung capacity at the beginning of the experiment was $811.2 \pm 21.1 \mathrm{ml}$, at the end of the experiment $-880.4 \pm 5.7 \mathrm{ml}$, the differences are reliable. Growth rate was $13.9 \%$. Hearth rate in children at the beginning of the experiment was $83.15 \pm 1.3$ beats per minute, at the end of the experiment $-80.2 \pm 0.02$ beats per minute, $\mathrm{p}<0.05$, the difference is reliable. The growth rate was $13.9 \%$. 
Table 1: Dynamics of indicators of physical development of preschool children aged 6-7 during the 2-year experiment

\begin{tabular}{|c|c|c|c|c|c|}
\hline $\begin{array}{l}\text { № } \\
\Pi / \Pi \\
\end{array}$ & \multicolumn{2}{|c|}{ Physical development indicators } & $\begin{array}{l}\text { The beginning of the } \\
\text { experiment }\end{array}$ & The end of the experiment & $\begin{array}{l}\text { Reliability of } \\
\text { differences }\end{array}$ \\
\hline 1 & \multicolumn{2}{|l|}{ Body length, cm } & $120,1 \pm 1,1$ & $123,0 \pm 1,1$ & $\mathrm{t}=2,56 \mathrm{p}<0,05$ \\
\hline 2 & \multicolumn{2}{|l|}{ Body weight, kg } & $20,14 \pm 0,98$ & $23,56 \pm 1,1$ & $\mathrm{t}=2,43 \mathrm{p}<0,05$ \\
\hline \multirow{2}{*}{3} & \multirow{2}{*}{$\begin{array}{l}\text { Maximum force } \\
\text { brushes, } \mathrm{kg}\end{array}$} & left & $3,3 \pm 0,1$ & $3,7 \pm 0,09$ & $\mathrm{t}=2,39 \mathrm{p}<0,05$ \\
\hline & & right & $4,27 \pm 0,2$ & $4,78 \pm 0,11$ & $\mathrm{t}=2,45 \mathrm{p}<0,05$ \\
\hline 4 & \multicolumn{2}{|l|}{ Lung capacity, ml } & $811,2 \pm 21,1$ & $880,4 \pm 5,7$ & $\mathrm{t}=2,54 \quad \mathrm{p}<0,05$ \\
\hline \multirow{2}{*}{5} & \multirow{2}{*}{$\begin{array}{l}\text { AP, mm mercury } \\
\text { column }\end{array}$} & systolic & $79,7 \pm 2,4$ & $78,7 \pm 2,17$ & $\mathrm{t}=1,98 \mathrm{p}>0,05$ \\
\hline & & diastolic & $48,94 \pm 1,5$ & $49,05 \pm 1,2$ & $\mathrm{t}=0,41 \mathrm{p}>0,05$ \\
\hline 6 & \multicolumn{2}{|l|}{$\mathrm{HR}$, beat/minute } & $83,15 \pm 1,3$ & $80,2 \pm 0,02$ & $\mathrm{t}=2,54 \mathrm{p}<0,05$ \\
\hline
\end{tabular}

As a result of introducing steppe-aerobics into the process of physical education of preschool children, reliable differences in the indicators of physical fitness have been revealed. It was found that in the tests characterizing the indicators of flexibility and speed-force capabilities, preschoolers showed an average level of physical fitness, i.e. they switched from one level to another. And in the tests characterizing endurance, upper limb strength and muscle strength, pupils showed results corresponding to a level below average physical fitness, which also indicates a transition from one level to another. Figures 1 and 2 show the dynamics of physical fitness indicators in the tests of pulling up from a bed on a low bar and raising and lowering the torso from a bed on the floor for girls of the control group. Thus, the result at the beginning of the experiment in the test pull-up from the hanging of the bed on a low bar in girls was 6.2 times, which corresponded to a low level, at the end of the experiment - 8.3 times, which corresponds to a lower average level of physical fitness in the group.

The result at the beginning of the experiment in the test of raising and lowering the torso from the and so on the floor for girls was 6.7 times, which corresponded to a low level, at the end of the experiment - 9.1 times, which corresponds to a lower average level of physical fitness in the group. Figures 3 and 4 show the dynamics of the results of physical fitness of boys in the test of long jump and tilt forward. At the beginning of the experiment, the result in the test of the long jump from a place for boys was $1.2 \mathrm{~cm}$, which corresponded to a low level, at the end of the experiment $-3.2 \mathrm{~cm}$, which corresponds to a lower average level, the differences are reliable $(\mathrm{p}<0.05)$. In terms of endurance and speed, we also found reliable differences in the $300 \mathrm{~m}$ running test and $30 \mathrm{~m}$ running test dynamics for both boys and girls in the control group. At the beginning of the experiment the result in the test of the long jump from a place, in boys was $102.2 \mathrm{~cm}$, which corresponded to a low level, at the end of the experiment $-107.8 \mathrm{~cm}$, which corresponds to a lower average level, the differences are reliable $(\mathrm{p}<0.05)$. Thus, a differentiated approach to the content and organization of step aerobics training sessions provides a training effect for all children, regardless of their state of health, contribute to the improvement of the body's adaptive capacity based on individual indicators of physical and mental condition. Step aerobics classes are a means of overcoming difficulties associated with health limitations. In this regard, the expedient selection and rational use of steppe-platforms contributes to the formation of a variety of motor skills and abilities in children in the HIA, the development of physical qualities and creative abilities, education of moral and volitional qualities, increasing interest in various sports games and physical exercises. Children attending Steppe Aerobics classes actively and gladly take part in demonstration performances on holidays and matinee. The Steppe Aerobics class not only has a positive impact on the emotional color of the activity, children are happy to attend and wait for the class, but also on the development of physical abilities such as speed-force, coordination and flexibility.

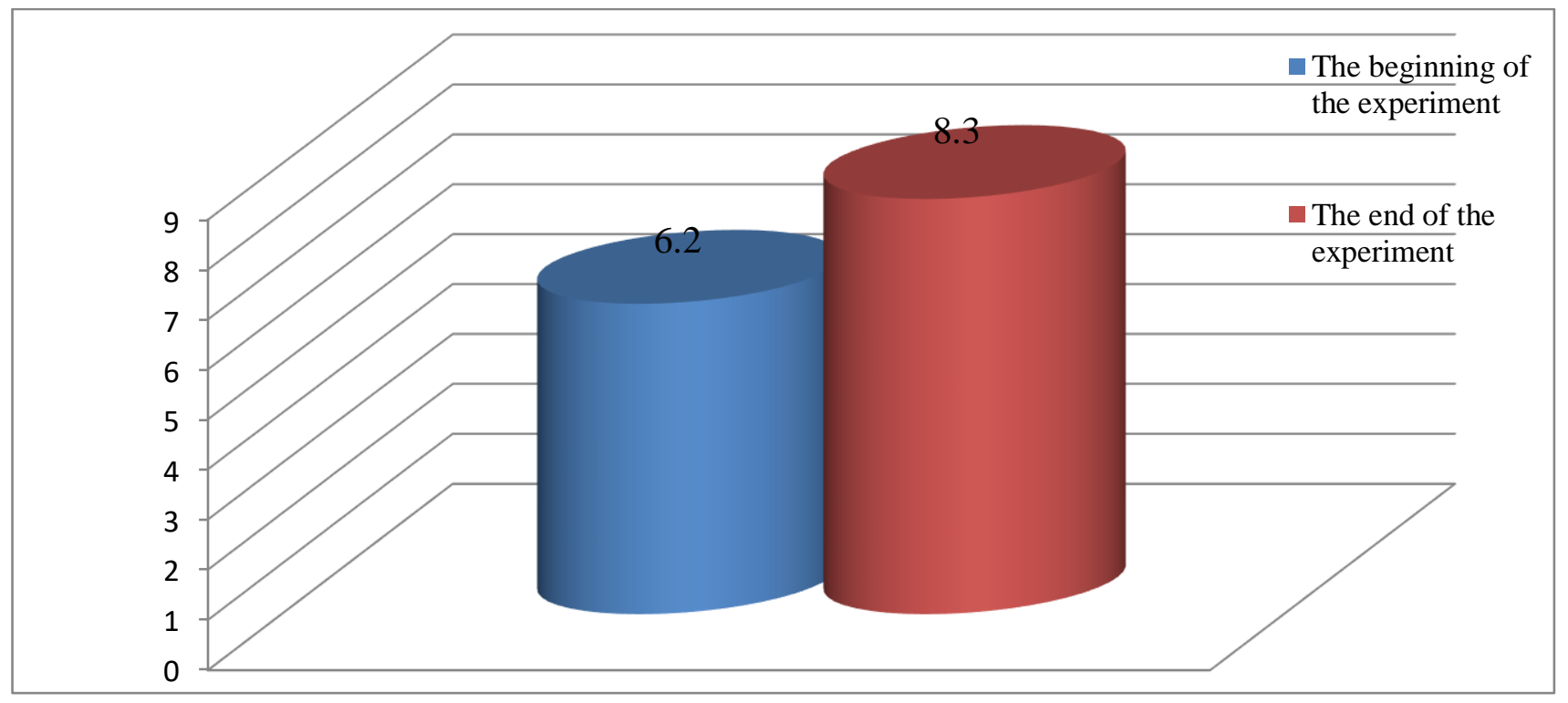

Figure 1: Dynamics of physical fitness in the test of pull-up from the hanging of the bed on a low bar in girls 


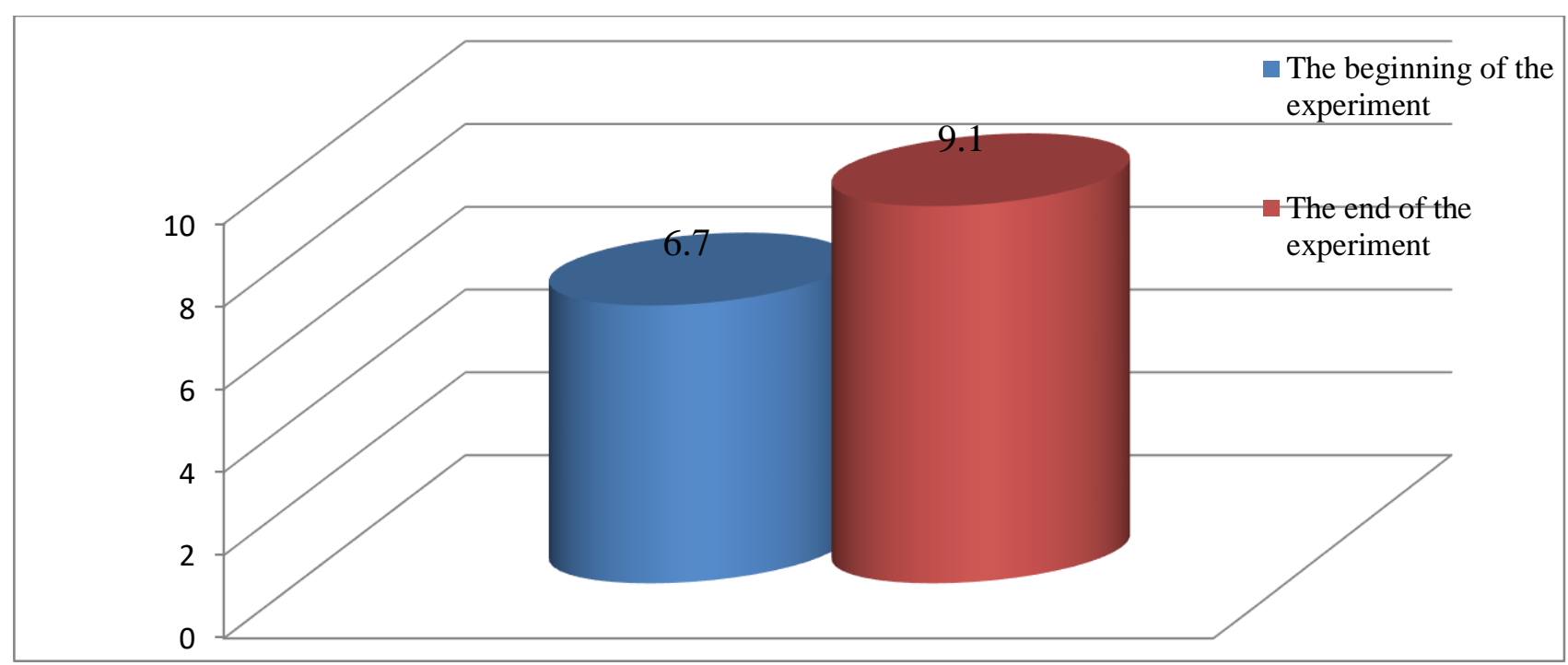

Figure 2: Dynamics of physical fitness indicators in the test of raising and lowering the torso from the floor on the floor of girls

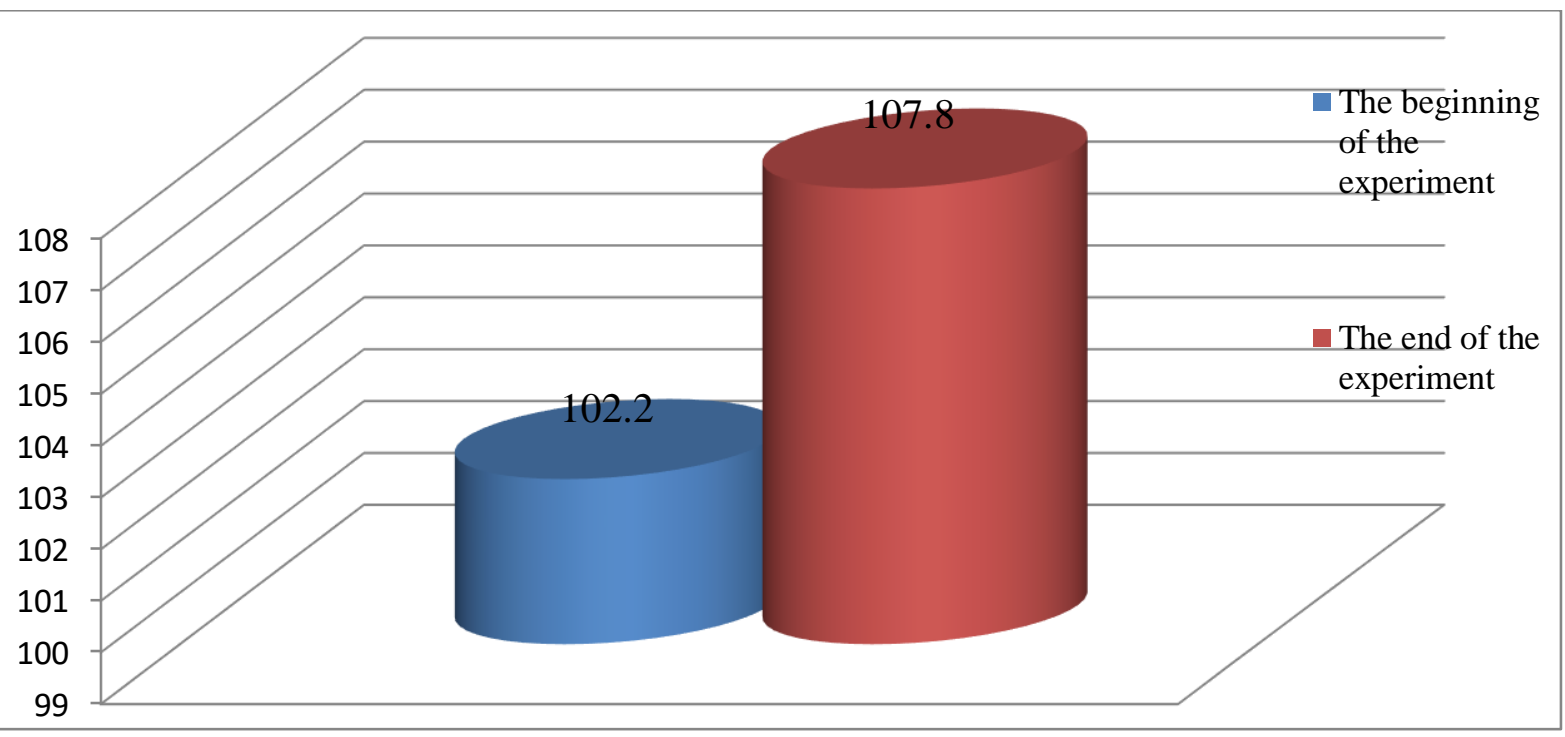

Figure 3: Dynamics of fitness scores in the long jump test for boys

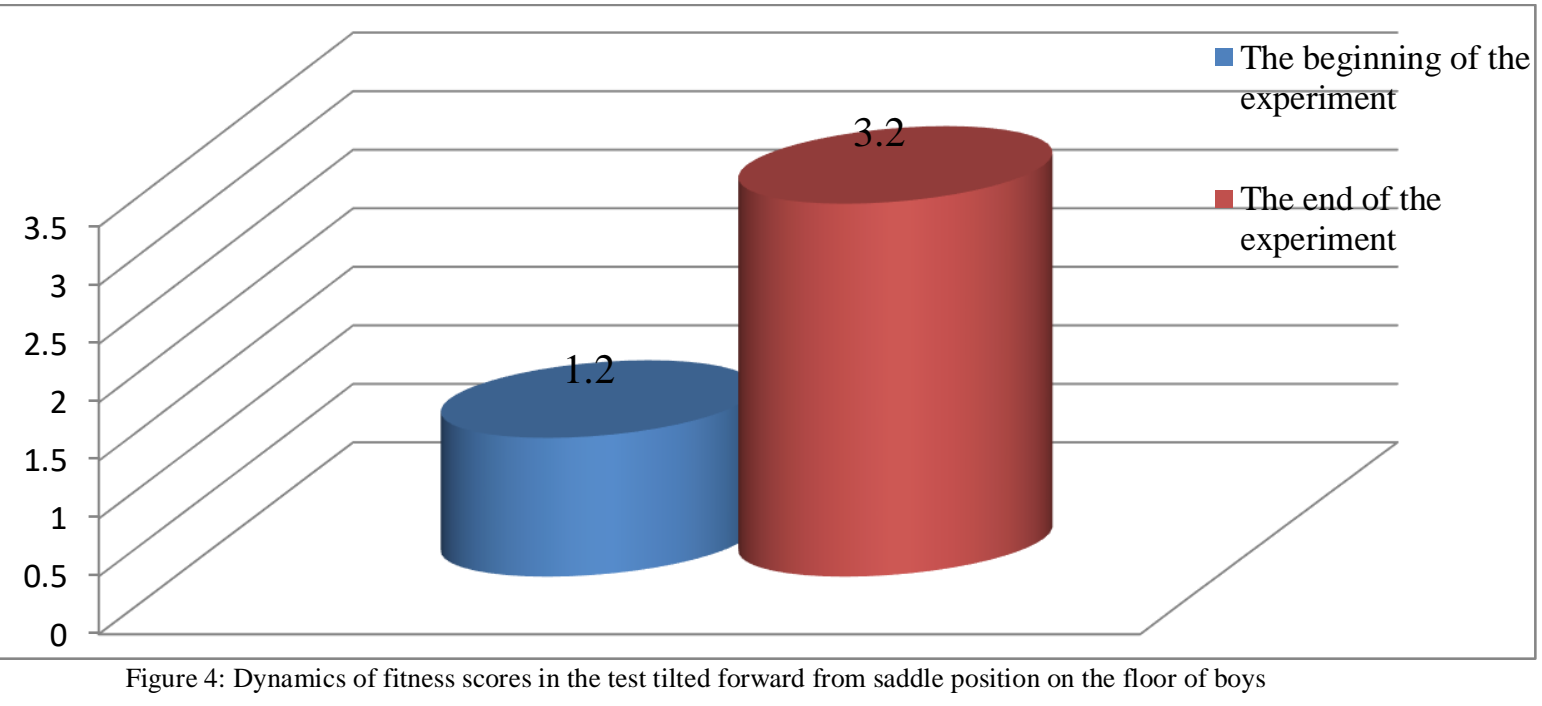

\section{Conclusion}

Currently, the problem of physical education of preschool age children is central to modern society. It is in this period that the foundations of health, correct physical development are laid, motor skills and interest in activities are formed. According to the data of the research institute of hygiene and 
health protection of children for the last 10 years up to $60 \%$ of children suffer from chronic diseases, $25-35 \%$ of children who came to the 1st grade have physical defects or chronic diseases.

Step-aerobics for children is the performance of a complex of exercises of different pace and intensity to musical accompaniment with the help of step-platform, in the process of which the work of the entire musculoskeletal system. Stepaerobics has a positive impact on the entire body, strengthening the respiratory, cardiovascular, muscular and nervous systems. In addition, during classes a positive psychological mood is created, the emotional level is increased, contributing to the development of thinking, imagination, creative abilities of children of preschool age.

Despite several studies on improving the process of physical education of preschool children, there are not enough practical developments and methodological recommendations for the widespread use of step aerobics in kindergartens with disabilities. In this regard, we have identified the methodological features that must be taken into account when conducting steppe-aerobics classes for children of older preschool age and have developed the content of recreational aerobics classes in preschool educational institutions for children with mental disabilities.

As a result of the introduction of step-aerobics into the process of physical education of preschool children with mental disorders, a reliable increase in the indicators of physical development and physical fitness during the experiment was identified.

\section{Recommendations}

When organizing steppe-aerobics classes with preschool children who have mental disabilities, the following methodological guidelines should be followed:

1) Basic methods of teaching aerobics, such as: practical demonstration, verbal commentary and explanation should be used. During the class, the instructions given during the exercise are of great importance. These instructions include the name of the movement, the main points of technique, direction, counting, etc.), to be explained in an accessible, understandable form, considering the age and delay in the mental development of children.

2) It is necessary to use visual methods of group management, which include expressive body movements and facial expressions. The leader should emphasize with his pantomime moments of relaxation, tension, character of dance elements, score, sequence of exercises, etc.

3) Correct use of musical accompaniment. Music should be considered as a factor of influence on those involved in aerobics in the process of training exercises by changing the pace and rhythm and melody of the musical accompaniment. The proper use of music helps the successful learning of motor skills. When composing musical phonograms, it is necessary to consider the gender and age of the occupants to avoid undesirable effects of musical works on the technique and psychology of children.

4) Using a methodical technique that affects the development of interest in step aerobics, which is to change the pace of movement: you can slow down or accelerate the pace depending on the stage of assimilation of an element, compound or the whole combination. Slow execution of movements is also not recommended, as in this case will reduce the impact on the cardio-respiratory system, and therefore the health effects on the body engaged.

5) The use of mirrors in the halls for step-aerobics is important for learning, technically correct exercise, for personal contact, communication with children. Simple to coordinate movements should be shown face to face with children from the left arm and leg "in the mirror reflection", complex - back to the occupants. When individual movements or combinations are mastered well enough, the leader turns around facing the children and performs the movements in "mirror reflection". The movements must be made in both directions.

6) Use of game orientation in step-aerobics classes for children of preschool age. Exercises should be accessible, interesting, and enjoyable, but remember that children get tired quickly and cannot make monotonous movements for long. The easiest way for a child of preschool age to learn and remember such exercises, which in his or her imagination will create a specific visual image. You can master step-aerobics, depicting animals that move identically.

7) The load must be adjusted by the following factors: (a) change in platform height. Increasing by $5 \mathrm{~cm}$ increases the intensity by $12 \%$. This is the most effective method of increasing the load, but it must take into account the preparedness of the workers and their weight. But in this group, we did not use this parameter. (b) The increase in music tempo from 80 to 120 beats per minute increases the intensity by $50 \%$, from 120 to 128 beats per minute - by $4.6 \%$. In terms of physiological impact on the body engaged in activities on the steppe-platform with music accompaniment of 120 accents / min is equal to running at a speed of $12 \mathrm{~km} / \mathrm{h}$.

\section{Ethical issue}

Authors are aware of, and comply with, best practice in publication ethics specifically with regard to authorship (avoidance of guest authorship), dual submission, manipulation of figures, competing interests and compliance with policies on research ethics. Authors adhere to publication requirements that submitted work is original and has not been published elsewhere in any language.

\section{Competing interests}

The authors declare that there is no conflict of interest that would prejudice the impartiality of this scientific work.

\section{Authors' contribution}

All authors of this study have a complete contribution for data collection, data analyses and manuscript writing.

\section{References}

[1] Aksenova NI. Increase of the motor activity level and a dosage of physical activity at physical training. Pre-school education. 2000;6:37-48

[2] Baranov AA, Albitsky VY, Modestov AA, Kosova SA and others Disease incidence of children's population of Russia (results of complex medical-statistical research).Zdravookhraneniye Rossiyskoy Federatsii.2012;5:21-26.

[3] Vorobyov NB, Voronin DI, Burkhanova IY, Ivanova SS, Stafeeva AV, Kiseliv YV, Bocharin IV. Physical health and the ways of sportsmen having success.EurAsian Journal of BioSciences.2019;13(2):1467-1471.

[4] Vinogradova NA. Physical development of preschool children. Part 1: Physical development of preschool children. Health protection and promotion. Moscow:TC Sphere.2015.

[5] Egorov BB. Actual problems of health of children of preschool age.Russian children are educated and healthy: materials of the 7th All-Russian Scientific and Practical Conference.2014:233-235.

[6] Vorobyov NB, Burkhanova IY, Bystritskaya EV, Ivanova SS, Stafeeva AV, Krasnova MS, Petrova LV. Development of Researh Skills in Future Physical Education Specialists. Modern journal of language teaching methods.2018;8(11):791-798.

[7] Kaminsky OA. To a question on perfection of an educational material for experts in physical culture of preschool children. Physical culture and sports at the turn of the millennium: Master. 
of All-Russian scientific - practical conf. St. Petersburg: Publishing house of Herzen State Pedagogical University.2011.

[8] Kirkina EN. Formation of a healthy way of life at senior preschoolers in the process of organization of physical culture and health activities. Science Time.2014;10:14-16.

[9] Kochneva EM, Grishina AV, Volozhanin SE. About creation of model of psychological and pedagogical support of positive parenthood. Vestnik of Minin University.2019;3(28):278-285.

[10] Makarenko VG. Pedagogical management of physical education of children of preschool age: abstract of Doctoral Dissetrarion. Chelyabinsk.2012.

[11]Burina EA., Kudinova AE. Features of the modern Russian family in conditions of social and historical changes of the Institute of Parenthood. Vestnik of Minin University.2020;8(1): 133-142.

[12] Novikova IM. Formation of ideas about the healthy way of life in preschool children: Methodical manual.Moscow:Mosaika sintez.2010.

[13] Stafeeva AV, Deryabin AL. Increase of functional readiness of girls of 18-25 years old by means of steppe-aerobics. Fundamental researches.2015;2(19):4315-4318.

[14] Stafeeva AV, Reutova OV. Justification of efficiency of traditional means and forms of physical culture and their influence on physical development and physical preparedness of preschool age children.Modern problems of science and education.2015;6:491503.

[15] Grigorieva EL, Stafeeva AV, Ivanova SS, Reutova OV, Zhemchug YS. Specifics of the integration of family and school physical education in multicultural society. Turismo: Estudos \& Práticas (UERN), Mossoró: Caderno Suplementar 02,2020. URL: http://natal.uern.br/periodicos/index.php/RTEP/index

[16] Prischepa SS. Physical development and health of children of 3-7 years.Moscow:Sfera.2009.

[17]Penzulaeva LI. Health-improving gymnastics for children of 3-7 years old. Mosaic-Synthesis.2009.

[18] Stepanenkova EY. Collection of mobile games. Moscow: MosaicSynthesis.2011.

[19]Bystritskaya, E.V., Ivanova, S.S., Burkhanova, I.Y., Stafeeva, A.V., Vorobyov, N.B., Dreiko, N.Y., Bobyleva, L.A. The role of rhizome model in future physical education teachers selfrealization. EurAsian Journal of BioSciences.2019;13(2):15811588.

[20] Sukhareva LM, Namazova-Baranova LS, Rapoport IK. Disease incidence of the Moscow schoolchildren in the dynamics of teaching from the first to the ninth grade.2013;4:48-53.

[21] Tarasova TA. Control of the physical condition of children of preschool age: methodological recommendations for managers and teachers of preschool institutions. Moscow: TC Sphere, 2012.

[22] Khairullina ER, Shubovich MM, Bogdanova VI, Slepneva EV, Mashkin NA, Rodyukova TN. Modern student youth civic identity: Political activity or social responsibility? Opcion.2020; 36:1703-1717.

[23] Chimarov VI. About the strategic orientations of children health formation in the educational institutions.Education and Science. 2015;1(3):87-94.

[24]Russu NV. Non-standard physical training equipment. Kindergarten child.2011;5:11-13.

[25] Mokina EA. Materials and equipment by own hands. Health of a preschooler.2011;2:7-8.

[26] Panasenko KE. Trends of the physical culture and healthimprovement activity in the modern preschool education. Young scientist.2016;1:743-745.

[27]Podymov NA, Nikoghosyan MA, Stolyarova AN, Narutto SV, Mashkin NA, Martynenko SE, Paznikova ZI, Varenik PK. University New Educational Reality in Disruptive Technologies Context. Journal of Environmental Treatment Techniques.2019; 7(4): 664-668

[28] Ovsyanik AI, Sidorenko GG, Prasolov VI, Aleksandrova NS, Mashkin NA, Pozdnyakova IR, Makarova EV. Remote education in modern university: Potential opportunities, quality or availability? International Journal of Psychosocial Rehabilitation.2020; 24(4):5027-5034.

[29]Cherdymova EI, Afanasjeva SA, Parkhomenko AG, Ponyavina MB, Yulova ES, Nesmeianova IA, Skutelnik OA. Student ecological consciousness as determining component of ecological- oriented activity. EurAsian Journal of BioSciences, 2018;12(2):167-174

[30] Khairullina ER, Bogdanova VI, Slepneva EV, Nizamutdinova GF, Fatkhullina LR, Kovalenko YA, Skutelnik OA. Global climate change: Cyclical nature of natural and permanent nature of manmade processes. EurAsian Journal of BioSciences, 2019;13(2):2311-2316 